\title{
Pasado, presente y futuro de la microbiología de la periodontitis
}

\author{
ESCRIBANO M* \\ MATESANZ P* \\ BASCONES A**
}

Escribano M, Matesanz P, Bascones A. Pasado, presente y futuro de la microbiología de la periodontitis. Av Periodon Implantol. 2005; 17, 2: 79-87.

\begin{abstract}
RESUIMEN
Es bien sabido que la periodontitis es una enfermedad de origen infeccioso, pero posee características propias que hacen difícil su conocimiento etiopatogénico, y en consecuencia, su tratamiento. Numerosos avances relacionados con el estudio microbiológico de la placa bacteriana se están llevando a cabo en los últimos años, con el objetivo de optimizar los recursos terapéuticos y ofrecer a los pacientes una atención clínica predecible basada en la evidencia científica. El objetivo de este artículo es el de revisar la literatura actual y hacer énfasis en los nuevos conceptos microbiológicos que determinarán el futuro de las investigaciones acerca del diagnóstico y tratamiento de la periodontitis.
\end{abstract}

\section{PALABRAS CLAVE}

Biofilm, bacterias periodontopatógenas, diagnóstico periodontal.

Aceptado para publicación: Abril 2005

\section{INTRODUCCIÓN}

La periodontitis es una enfermedad de origen bacteriano que debe entenderse como enfermedad infecciosa a pesar de las diferencias que parece presentar con otras patologías de este tipo. Tiene en común con todas ellas el hecho de estar obligatoriamente asociada a la presencia de las bacterias que colonizan el nicho subgingival, sin embargo la periodontitis tiene ciertas características que la hacen única. Puede que la característica más llamativa sea el hecho de que los dientes sean órganos que están parcialmente expuestos al medio externo, permitiendo así la colonización directa y el contacto íntimo con las bacterias.

Pero no son las bacterias las únicas contribuyentes a este cuadro. Recientemente, se han publicado estu- dios que ponen de manifiesto la asociación entre determinadas familias de virus y las enfermedades periodontales. Ya en 2000 Contreras y cols. demostraron la presencia de determinados virus, (Epstein-Barr tipo 1, citomegalovirus y virus del herpes humano), en el fluido crevicular de niños nigerianos con gingivitis ulcerosa necrotizante (1).

Las líneas de investigación más actuales destacan la posibilidad de que familias de virus como el citomegalovirus humano o el virus de Epstein-Barr tipo 1 puedan estar relacionados con los principales periodontopatógenos subgingivales, contribuyendo de este modo a la etiología y la evolución de la periodontitis (2). Pudiera ser que la infección gingival viral produjera un deterioro de los mecanismos defensivos del huésped, favoreciendo así la colonización bacteriana (2). 
En cualquier caso, para explicar la etiopatogenia de la periodontitis no se debe prestar atención exclusivamente a las bacterias. De hecho, éstas son las encargadas de estimular la respuesta del huésped, de la que se derivan las alteraciones tisulares que definen las lesiones típicas de la periodontitis, y no las bacterias per se (3). Algunas bacterias se ha demostrado que son capaces de colonizar los tejidos, como por ejemplo Actinobacillus actynomicetemcomitans o Porphyromonas gingivalis (4); estas bacterias invaden las células epiteliales y endoteliales. Sin embargo, sus principales efectos deletéreos sobre los tejidos del huésped no derivan exclusivamente de este acontecimiento, sino de la respuesta inflamatoria e inmunológica que son capaces de estimular.

La respuesta del huésped a las bacterias comprende la participación de factores celulares y humorales del sistema inmune, que interaccionan para eliminar las bacterias del hospedador y acaban dañando a la vez los tejidos.

Por otra parte, cabe destacar la influencia de factores ambientales (tabaco, estrés, etc.) y sistémicos (enfermedades sistémicas y síndromes congénitos) que actúan modulando la respuesta del hospedador, acelerando o enlenteciendo con ello la progresión de la enfermedad (5).

Puede decirse por tanto que las bacterias son condición necesaria, no suficiente, para que aparezca la periodontitis $(3,5)$.

\section{EVOLUCIÓN DE LAS TEORÍAS ACERCA DE LA COIMPOSICIÓN DE LA PLACA}

La búsqueda de los microorganismos causantes de las enfermedades periodontales ha sido motivo de estudio durante los últimos 100 años. A principios del siglo XX, al tiempo que comenzaban a encontrarse los agentes etiológicos de otras enfermedades, empezó a investigarse cuál podría ser la causa de que una parte de la población desarrollara un cuadro clínico tras el cual acababan perdiéndose los dientes (6). Sin embargo, los resultados no fueron tan reveladores como los de otras localizaciones del organismo y tuvo que continuar la búsqueda.

Tras esto, se empezó a otorgar un cierto protagonismo a distintos grupos de microorganismos, como a las amebas, las espiroquetas, los estreptococos y las bacterias fusiformes. Las técnicas en aquellos tiempos eran limitadas; para la identificación no se contaba más que con técnicas de tinción y ciertos cultivos muy limitados. El desarrollo de las técnicas ha despertado nuevos planteamientos, aunque hoy en día también existen limitaciones para la identificación.

Sin embargo, esta idea inicial acerca del origen bacteriano de la periodontitis fue poco a poco desapareciendo y dio lugar a una segunda corriente de pensamiento, en la que se creía que el origen estaba en alguna alteración constitucional o funcional del paciente, y que las bacterias no eran más que colonizadores secundarios de la enfermedad (6).

Las distintas teorías se han ido sucediendo a lo largo del pasado siglo; se retomó la idea del origen bacteriano, pero pensando más en una placa bacteriana de tipo inespecífico. De acuerdo a esta corriente de pensamiento, la mera presencia de bacterias bajo la encía, independientemente de su naturaleza, actuaría como factor irritante, originando la inflamación de los tejidos.

El primer estudio que demuestra que la presencia de placa es el requisito imprescindible y desencadenante para la aparición de las alteraciones periodontales, (en concreto de la gingivitis), es el de Löe y Theilade de los años 60 (7). Este estudio supone la confirmación de las teorías hasta entonces sospechadas acerca de la importancia de la placa a la hora de desarrollar gingivitis. Sin embargo, tras este estudio aún quedaban muchas cuestiones sin resolver; si se parte de la base que la gingivitis se origina como consecuencia de la placa y, tras ella, en ocasiones se desencadena un cuadro de periodontitis, ¿por qué existen ciertos individuos que a pesar de tener grandes depósitos de placa no llegan a desarrollar periodontitis?

A partir de este momento se comienza a buscar los agentes que en cada caso pueden estar causando la enfermedad. De esta época son los estudios de Newman (1976), Tanner (1979) o Slots (1977), en los que se toman muestras en localizaciones enfermas y se consigue llegar a la conclusión de que la microbiota de dichas localizaciones es distinta de la de individuos sanos e, incluso, de la de los mismos individuos pero en otras localizaciones (8-10).

A estos estudios se añade el buen resultado del tratamiento cuando se asocian antibióticos, lo cual acaba por confirmar la participación de microorganismos específicos en la etiología de las diferentes enfermedades periodontales.

\section{CONCEPTOS ACTUALES}

\section{Concepto de biofilm}

El concepto de placa dental entendida como biofilm 
ha sido revisado recientemente. De acuerdo con este concepto, las bacterias no se disponen de forma arbitraria y aislada dentro de la propia placa, sino que ocupan un lugar y una función determinada y específica en la estructura del biofilm (11).

Los biofilms están formados por una o más comunidades de microorganismos, embebidos en un glicocálix, unidos a una superficie sólida. La razón por la que existen los biofilms en la naturaleza es que permiten a los microorganismos unirse y multiplicarse sobre distintas superficies. Además, las bacterias que forman parte de un biofilm (sésiles) disfrutan de un gran número de ventajas en comparación con las bacterias aisladas (plantónicas) (12).

La mayor ventaja que ofrece el biofilm a las bacterias sésiles es la de protección frente a microorganismos competidores, frente a sustancias potencialmente tóxicas del medio procedentes del sistema defensivo del hospedador y frente a sustancias antibióticas. Además, el biofilm facilita la captación de nutrientes, la alimentación cruzada (una especie provee a otra de nutrientes), la eliminación de productos metabólicos potencialmente dañinos y el desarrollo de un ambiente con las condiciones fisicoquímicas apropiadas para el desarrollo de los microorganismos que lo forman (13).

El estudio de los biofilms es técnicamente muy difícil, en parte por su naturaleza microscópica y en parte por la complejidad de las relaciones interbacterianas que tienen lugar en el ecosistema propio del biofilm (13).

La propia estructura del biofilm hace que tenga una serie de características que van a condicionar su comportamiento. Las más importantes, según Costerton y cols. (2003), hacen referencia a la heterogeneidad fisiológica, a los distintos fenotipos encontrados entre bacterias sésiles y plantónicas, a las señales emitidas dentro del biofilm, donde destaca el concepto de quorum sensing, y a la capacidad adaptativa de las bacterias que se organizan de forma altamente específica para lograr un equilibrio entre la necesidad de maximizar el área de superficie para el intercambio de nutrientes y la cohesión que lo permita permanecer unido a la superficie (14).

En los últimos años, se han dado importantes avances en cuanto al conocimiento de la organización de los biofilms y de los modos en los que se establece la comunicación interbacteriana que hace que sean estructuras organizativamente muy complejas. El fenómeno de quorum sensing y su importancia dentro del desarrollo de los biofilms bacterianos fue descrito por primera vez por Cooper y cols. en 1995.

Algunas de las funciones de los biofilms dependen de la habilidad de las bacterias para comunicarse entre ellas. Con quorum sensing se hace referencia a la regulación de la expresión de determinados genes a través de la acumulación de compuestos señalizadores que median la comunicación intercelular. El quorum sensing depende de la densidad celular. Cuando la densidad celular de un biofilm es baja, los compuestos señalizadores se producen en pequeñas cantidades, si bien, la autoinducción hace que se incrementen estos niveles a medida que la densidad celular también aumenta. Una vez que estos compuestos alcanzan un nivel umbral (densidad celular de quorum) comienza la activación de la expresión genética. El fenómeno de quorum sensing da al biofilm propiedades distintivas, además de influir en la estructura de la comunidad bacteriana favoreciendo el crecimiento de bacterias beneficiosas para el biofilm e impidiendo el desarrollo de especies competidoras (13).

Los biofilms que colonizan la cavidad oral son unos de los más complejos biofilms que existen en la naturaleza. Esta complejidad se debe en gran medida a la composición de las distintas superficies, que determinan la existencia de cuatro nichos orales diferentes (15): mucosa masticatoria, dorso lingual, saliva y superficies duras, en donde se incluyen las superficies dentarias y las de materiales de restauración.

Las bacterias asociadas a la periodontitis residen tanto en biofilms que se encuentran por encima como por debajo del margen gingival. El biofilm supragingival está unido a la superficie dentaria y está formado predominantemente por Actinomyces. Sin embargo, la naturaleza del biofilm subgingival es más complicada, ya que existen dos biofilms diferentes, uno asociado a la superficie radicular y otro en íntima relación con la superficie epitelial de la pared blanda de la bolsa. Este último contiene, predominantemente, espiroquetas y especies gram negativas ( $P$. gingivalis, Treponema denticola, etc). Entre estos dos biofilms existe una zona de baja densidad celular compuesta por bacterias débilmente unidas que parecen estar en estado plantónico $(4,13)$.

Al hablar de la periodontitis como enfermedad infecciosa se parte de la premisa de que para darse, debe darse la presencia y multiplicación de organismos en el cuerpo (5). Hoy se sabe que para que aparezca esta infección, es necesario que intervengan una serie de bacterias, que se acumulan y producen factores de virulencia, por medio de los cuales van dañando los tejidos. El conjunto de las enfermedades periodontales está causado por microorganismos que se asocian y colonizan la superficie dentaria o el interior del surco periodontal (13), desde donde origina la enfermedad. Dichas asociaciones no se establecen al azar, sino de manera específica y ordenada de acuerdo a unos códigos de color o clusters, que marcan la patogenicidad de la asociación. 
De entre todas las bacterias que forman el biofilm bacteriano existen tres que tienen una relevancia especial en el inicio y la progresión de la enfermedad, son Actinobacillus actinomycetemcomitans (Aa), Porphyromonas gingivalis $(\mathrm{Pg})$ y Tannerella forsythensis (Tf) (16). El origen de estas especies es exógeno; no forman parte de la flora habitual y el tratamiento debe tener como objetivo su eliminación total (17).

La presencia de estas bacterias puede determinarse inicialmente por medio del cultivo, que ha sido la técnica de elección durante muchos años. Sin embargo, el desarrollo de la ciencia y la tecnología permite completar el diagnóstico con otras técnicas que sirven para confirmar, como por ejemplo la PCR.

A pesar de la dificultad para analizar la composición del biofilm bacteriano en individuos sanos frente a individuos con periodontitis, es posible establecer qué bacterias forman parte de lo que podrían denominarse periodontopatógenos por su participación en la aparición de la enfermedad periodontal.

De entre todas las especies bacterianas, la que parece predominar tanto en individuos sanos como enfermos es Actinomyces, tanto en la placa supragingival, como en la subgingival.

Las bacterias causantes de la enfermedad periodontal pueden clasificarse en grupos, en función de las asociaciones que entre ellas se establecen a la hora de colonizar el surco periodontal (13):

- Amarillo: bacterias del género Streptococcus.

- Verde: Capnocytophaga spp, A. actinomicetemcomitans serotipo a, E. corrodens y Campylobacter concisus.

- Púrpura: Actinomyces odontoliticus, Veillonella parvula.

- Azul: Actinomyces spp.

- Naranja: Campylobacter gracilis, Campylobacter rectus, Eubacterium nodatum, Campylobacter showae, Fusobacterium nucleatum, Fusobacterium periodonticum, Peptostreptococcus micros, Prevotella intermedia, Prevotella nigrescens y Streptococcus constellatus.

- Rojo: T. forsythensis, T. denticola y P .gingivalis.

- Bacterias que no pertenecen a ningún cluster, como es el caso de $A$. actinomycetemcomitans serotipo b.

Las diferencias principales entre salud y enfermedad se basan en el predominio de los clusters rojo y naranja, que, por otro lado, son a su vez mucho más prevalentes en la placa subgingival que en la placa supragingival.
En cualquier caso, estos datos no pueden tomarse como definitivos; la dificultad de los estudios para determinar con seguridad qué bacterias forman el biofilm pone de manifiesto la necesidad de llevar a cabo más investigaciones al respecto. Es importante determinar la composición de los biofilms en cada persona de forma individual, ya que esto puede acarrear grandes diferencias a la hora de plantear el tratamiento.

Se ha escrito mucho acerca de la etiología bacteriana de la periodontitis y hoy en día se acepta que son muchas bacterias, y no una sola, las implicadas en la aparición de la enfermedad. Alrededor de 500 bacterias distintas pueden colonizar el nicho subgingival, y sin embargo a día de hoy se estima que alrededor de 300 todavía estén sin identificar (4).

Las diferencias en la composición del biofilm de individuos sanos e individuos con periodontitis es una idea que parte de los años 70 y sin embargo aún permanece vigente (8-10). Estudios actuales demuestran la existencia de ciertas bacterias periodontopatógenas íntimamente relacionadas con la etiología de este cuadro, que en raras ocasiones pueden ponerse de manifiesto en individuos sanos. Es el caso por ejemplo de P. gingivalis o T. forsythensis.

A pesar de que hoy se trabaja con la idea de que puedan existir una serie de individuos que pueden ser portadores de determinadas bacterias altamente relacionadas con la periodontitis sin llegar nunca a desarrollar la enfermedad (estado de portador sano), los estudios demuestran que las bacterias del cluster rojo se localizan principalmente en individuos con la enfermedad activa (17).

En cuanto a la presencia de estas mismas bacterias en relación con la edad, la mayoría de estudios reflejan que no existen diferencias estadísticamente significativas entre la prevalencia de $P$. gingivalis y T. forsythensis en distintos grupos de edad siempre y cuando todos presenten en el momento de la toma de muestras periodontitis en estado activo (17).

Otra línea de investigación abierta en la actualidad tiene que ver con la naturaleza de las bacterias que forman el biofilm en individuos de distintas partes del mundo. Se han llevado a cabo estudios analizando este hecho y se ha visto que los resultados acerca de la composición del biofilm de los individuos de una localización geográfica no son extrapolables a otras localizaciones $(16,18)$. Por citar un ejemplo, en un estudio llevado a cabo en Brasil, Chile, Suecia y E.E.U.U. en 2004, se vio que es más fácil encontrar T. denticola en los individuos brasileños y T. forsythensis y $P$. gingivalis en los chilenos. Aunque el estudio tiene sus limitaciones, las conclusiones que propone coinci- 
den con las de otros estudios similares, poniéndose así de manifiesto que las proporciones en las que aparecen las bacterias en las muestras de placa subgingival en individuos con periodontitis crónica varían según la localización geográfica (18).

Hoy en día se está investigando también la posibilidad de que la periodontitis pueda tener efectos a distancia y generar efectos indeseados en otras partes del organismo. La evidencia científica ha puesto de manifiesto una relación entre la enfermedad periodontal y determinadas enfermedades sistémicas de carácter cardiovascular, pulmonar y endocrino (diabetes mellitus) así como con alteraciones en la gestación. Dada la gravedad de estos procesos y aun a falta de estudios que cuantifiquen la asociación entre estas patologías, se corrobora la importancia de establecer un temprano y adecuado tratamiento de la enfermedad periodontal, para reducir no sólo la morbilidad de la infección a nivel local, sino para actuar, indirectamente, sobre la salud general (19-27).

\section{TRANSMISIÓN DEL AGENTE ETIOLÓGICO}

Cabe la posibilidad de que la periodontitis, como enfermedad infecciosa que es, pueda transmitirse entre sujetos, como ocurre con la gripe, la mononucleosis, o cualquier infección en la que el agente etiológico pueda colonizar un nuevo individuo a partir de otro previamente infectado.

El plantear las enfermedades odontogénicas como enfermedades infecciosas suscita de inmediato una pregunta: ¿cabe la posibilidad de que estas infecciones se transmitan entre individuos? A la vista de las investigaciones que se llevaron a cabo en la pasada década, la respuesta a esta pregunta parece ser afirmativa; la transmisión de bacterias entre parejas, padres e hijos, hermanos e incluso entre humanos y animales parece ser posible (28-31).

El origen de la transmisión de patógenos reside en la saliva. Es posible constatar la presencia de patógenos periodontales en la saliva de pacientes con periodontitis, de manera que es posible que ésta actúe de vehículo de transmisión y traslade las bacterias desde el individuo portador a su pareja. El análisis del DNA de las bacterias aisladas de la boca de un paciente, ha hecho posible observar si las bacterias provienen de una misma cepa o de capas distintas.

En un estudio llevado a cabo a principios de los 90 se demostró que, las parejas de algunos individuos portadores de $P$. gingivalis poseen asimismo esta bacteria en su placa bacteriana. Por otra parte, al estudiar el DNA de $P$. gingivalis en ambas partes de la pareja, se ha visto que el DNA de las bacterias de un porcentaje elevado de pacientes con periodontitis resulta prácticamente indistinguible del de sus respectivos cónyuges (28). Lo que por el momento se desconoce es el alcance clínico real de la transmisión de patógenos, ya que en ocasiones, a pesar de poseer el agente infectante, las parejas de los pacientes con periodontitis no desarrollan la enfermedad. Esto puede ser atribuido a la respuesta del huésped, a sus mecanismos de defensa frente a las bacterias, aunque pudiera ser que en realidad se debiera a una menor capacidad infectante de las bacterias (32).

La transmisión de microorganismos se ha estudiado también entre hermanos y entre padres e hijos, y en estos casos también parece ser posible. Los estudios demuestran una cierta correlación en el estado periodontal de los individuos de una familia. De hecho, se ha valorado que la llegada de determinados microorganismos, como es el caso de $A$. actinomycetemcomitans, que determina la aparición de formas agresivas de periodontitis en individuos de corta edad, se produzca por el contacto con un padre previamente infectado en algún momento durante la infancia (30).

Existen además estudios que buscan la posible transmisión de patógenos entre distintas especies, a propósito de lo cual existe un caso publicado en 1988, en el que se describe la posibilidad de que los perros actúen como vectores de la infección. Esta es la conclusión a la que se llegó tras la observación de un niño que poseía la misma cepa de $A$. actimomycetemcomitans que su perro. Por otra parte, otro perro de la misma camada y su dueño, (otro niño), que vivían en otra parte del país, tenían el mismo clon (31).

Con estos estudios queda demostrada la posibilidad de que determinadas bacterias que no suelen encontrarse en la boca de individuos sanos, pueden colonizar los nichos orales de otros pacientes a través de la saliva de individuos portadores. A pesar de esta transmisión, la aparición de la enfermedad estará determinada no sólo por la presencia de las bacterias, sino por la susceptibilidad individual de cada individuo, como posteriormente se comentará. A pesar de todo, queda la duda de si la presencia mantenida de determinadas bacterias pudiera ser capaz de vencer a los propios mecanismos defensivos del hospedador y originar la enfermedad, a pesar de no ser un individuo originalmente susceptible.

\section{DIAGNÓSTICO MICROBIOLÓGICO}

Aunque en los tiempos que corren parece estar clara 
la etiología infecciosa de las enfermedades periodontales, siguen haciéndose grandes avances en las técnicas diagnósticas y en las consideraciones terapéuticas de esta enfermedad. Los avances de la ciencia hacen cada día más posible el reconocimiento de esta patología, así como de sus agentes causales, pudiéndose de este modo abordar el tratamiento de un modo más individualizado, específico para el paciente en cuestión, y no de forma general y exclusivamente empírica, como se hacía antes.

Las técnicas empleadas hoy para el diagnóstico microbiológico permiten acotar cada vez más las bacterias implicadas en cada caso de periodontitis, sin embargo, todavía no se conoce la manera en que cada una de ellas interactúan con el hospedador para dar paso a la enfermedad y, al mismo tiempo, todavía hoy existen especies bacterianas que no pueden ser diagnosticadas por los métodos de rutina.

Aunque el diagnóstico clínico y radiológico han sido durante mucho tiempo las técnicas rutinarias para plantear el manejo de los pacientes con periodontitis, la posibilidad de que los tejidos periodontales estén colonizados por bacterias de origen exógeno cambia mucho el plan de tratamiento, ya que introduce la necesidad de combinar el tratamiento convencional con el tratamiento antibiótico, lo cual hace necesaria la incorporación de las técnicas de diagnóstico microbiológico para así saber a qué especies bacterianas vamos a enfrentarnos (33).

Con la idea de reflejar la evidencia científica que existe actualmente acerca de la utilidad del diagnóstico microbiológico para poder enfocar más adecuadamente el tratamiento de los pacientes periodontales, se llevó a cabo una revisión sistemática en el año 2003 , en la que se analizaron todos los estudios al respecto realizados hasta la fecha (34). En esta revisión se llega a la conclusión de que el adecuado diagnóstico microbiológico reduce el número de periodontitis refractarias al tratamiento y, por otro lado, reduce el número de tratamientos quirúrgicos, ya que si se combina adecuadamente el tratamiento antibiótico con el raspado y alisado radicular en los casos pertinentes, desaparece la necesidad de intervenir quirúrgicamente al paciente para detener el avance de su enfermedad periodontal (34).

Puede decirse que el óptimo diagnóstico se consigue realizando, además de las pruebas de rutina, el diagnóstico microbiológico, y éste va a ser crucial para enfocar adecuadamente el plan de tratamiento (34).

Son varios los métodos desarrollados para el diagnóstico microbiológico en los últimos tiempos. Sin embargo, el objetivo perseguido por ellos puede variar en algunos casos, ya que en ocasiones se emplean exclusivamente con finalidad investigadora mientras que, en otros casos, han sido modificados y adaptados a las necesidades clínicas (35):

\section{Cultivo bacteriano}

A pesar del avance del resto de técnicas, el cultivo sigue siendo el método de referencia (gold standard) para el diagnóstico microbiológico, ya que sirve para determinar la presencia de las diferentes especies bacterianas, así como para valorar las susceptibilidades de éstas a los distintos antibióticos (32). Por otra parte, esta técnica permite estimar el número total de bacterias aisladas.

Como aspectos negativos cabe destacar la dificultad para mantener la viabilidad de las bacterias tras la toma de muestras, sin la cual se hace imposible el cultivo. Además, existen bacterias íntimamente relacionadas con la etiología de la periodontitis que no son cultivables y, por tanto, no detectables por medio de esta técnica, como T. denticola y T. forsythensis.

\section{Métodos de diagnóstico inmunológico}

Dentro de este grupo pueden destacarse varias técnicas como la inmunofluorescencia directa, la inmunofluorescencia indirecta, la citometría del flujo, la aglutinación por látex, y el test de E.L.I.S.A (enzyme-linked immunoabsorbent assay).

Todas estas técnicas nos sirven tanto para establecer la naturaleza de las bacterias que forman el biofilm como para calcular los porcentajes en que están presentes, además cuentan con una sensibilidad y especificidad ligeramente superior a las del cultivo (35). Sin embargo, a diferencia de la anterior, no sirven para evaluar las susceptibilidades bacterianas.

\section{Métodos de detección enzimática}

La reacción BANA hace posible el diagnóstico de ciertas especies bacterianas ( $T$.forsythensis, $P$. gingivalis, Capnocytophaga y T. denticola), capaces de producir enzimas trípsicas como factor de virulencia (36). Una reacción BANA positiva pone de manifiesto la presencia de cualquiera de estas cuatro especies bacterianas de una manera rápida y sencilla. Sin embargo, la baja especificidad y sensibilidad de estas técnicas es posible que las retire pronto del mercado.

\section{Técnicas de biología molecular}

Los principios de estas técnicas se basan en el análisis 
del DNA o el RNA. Se aísla la cadena de DNA de una muestra de placa y se amplifica. Tras su extracción y purificación, pueden emplearse diferentes técnicas para su identificación (sondas, checkerboard DNADNA, PCR), para lo cual es necesario identificar la especie bacteriana que posee el DNA aislado.

Dentro de estas técnicas, la más importante es la PCR, que permite amplificar las cadenas de DNA. Para ello, lo primero es aislar el DNA de la muestra y posteriormente aplicarle calor para separar ambas cadenas. Tras esto, utilizando DNA polimerasa y un primer o una secuencia conocida de nucleótidos, la muestra es amplificada y posteriormente visualizada.

Esta técnica tiene como aspecto positivo la elevada especificidad, sin embargo tienen como inconveniente la facilidad con la que puede contaminarse el proceso. Sirve para el diagnóstico de las principales bacterias periodontopatógenas, sin embargo, presenta limitaciones a la hora de cuantificar las cantidades en que se presentan cada una de ellas en las muestras recogidas. Esta limitación reduce su aplicación como método de diagnóstico convencional y ha puesto de manifiesto la necesidad de diseñar nuevas técnicas que permitan solucionar estos aspectos. Con la finalidad de reducir estos inconvenientes fue diseñada la PCR cuantitativa, que sirve como técnica complementaria al cultivo, el cual, por otra parte, sigue siendo la técnica de elección para la práctica clínica habitual (35).

\section{RELEVANCIA CLÍNICA DEL BIOFILIM EN EL ENFOQUE TERAPÉUTICO}

La importancia clínica de los biofilms orales surge ante la búsqueda de una terapia eficaz que permita erradicar aquellas bacterias periodontopatógenas que son responsables de la pérdida de inserción y, por tanto, modificar la estructura de este biofilm para evitar la recolonización por parte de estos patógenos. Pero este hecho está muy lejos de ser un objetivo sencillo de alcanzar. Autores como Stoodley y cols. defienden que los biofilms microbianos constituyen la estrategia vital defensiva más eficaz adoptada por células procariotas, que les permite hacer frente a innumerables condiciones hostiles del medio, y más concretamente, a sustancias potencialmente letales como los antibióticos, lo que dificulta enormemente su tratamiento (12). Ésta es la causa por la que se están llevando a cabo numerosos estudios, no sólo referentes a microbiología oral, para evaluar y mejorar el efecto antibiótico en bacterias pertenecientes a la estructura de un biofilm (37).

Según Costerton y cols., la resistencia que poseen las bacterias que forman parte de un biofilm con respecto a la que poseen las bacterias plantónicas se estima entre 1000 y 1500 veces superior. Esto hace que queden invalidados los estudios sobre susceptibilidad antimicrobiana que se llevan a cabo sobre bacterias aisladas, y abre, por tanto, una nueva línea de investigación (14).

Los mecanismos por los que las bacterias sésiles son más resistentes a los antimicrobianos que las plantónicas son muy numerosos (4). Además, estos mecanismos difieren no sólo entre distintas especies, sino ante distintos antimicrobianos y entre los distintos hábitat en los que se desarrolla el biofilm (13). Uno de los más importantes mecanismos de resistencia parece ser la baja tasa de crecimiento que tienen las bacterias dentro del biofilm, que las hace menos susceptibles a muchos, aunque no a todos los antibióticos (38). Además, la resistencia de las bacterias a los antibióticos está afectada por su estado nutricional, la tasa de crecimiento, la temperatura, el pH y la exposición previa a dosis subletales del agente antibiótico. Cualquier variación de estos parámetros puede modificar la respuesta a los antibióticos de las bacterias del biofilm. Además, las bacterias del biofilm están embebidas en una matriz que, aunque no actúa de barrera propiamente dicha, retarda la difusión del agente antimicrobiano. A todos estos mecanismos, hay que sumar el potencial de las enzimas que segregan las bacterias al espacio extracelular, como las $\beta$-lactamasas, formaldehído deshidrogenasa, etc., que suponen la ineficacia de determinados antibióticos (13).

Todos estos procesos no explican totalmente la resistencia de las bacterias del biofilm a los antimicrobianos. Las últimas investigaciones al respecto proponen la idea de que existan subpoblaciones de bacterias "súper-resistentes", que poseerían elevados niveles de resistencia antibiótica (13).

Puesto que la eliminación completa del biofilm sólo puede hacerse con terapia mecánica (control mecánico de placa supragingival, raspado y alisado radicular y cirugía periodontal) y la duración en el tiempo de esta "ausencia de biofilm" es muy limitada (apenas unas horas), se han estudiado diferentes combinaciones terapéuticas con el fin de mejorar su potencial y mantener en el tiempo la condición de salud gingival. La terapia mecánica practicada de forma aislada obligaría al biofilm a estructurarse de nuevo pero bajo condiciones ambientales diferentes (debido a la mejora de los parámetros clínicos de inflamación). Si a esta forma terapéutica se le suma el efecto microbicida de la terapia antibiótica es de esperar que los resultados terapéuticos sean sustancialmente más favorables, puesto que se modificaría no sólo la situación cuantitativa sino también cualitativa del biofilm. Esta línea de tratamiento es la que se lleva a cabo en los casos de periodontitis refractarias, periodontitis agresivas y periodontitis asociadas a 
desórdenes sistémicos, donde se administra terapia antibiótica de forma coadyuvante a la terapia mecánica (15).

Ésta es la causa de que hayan aparecido en los últimos años numerosas investigaciones acerca de cómo afecta la terapéutica mecánica periodontal a la composición cualitativa del biofilm, puesto que sólo algunas bacterias están fuertemente asociadas con la pérdida de inserción periodontal, y es su erradicación el objetivo final del tratamiento y mantenimiento periodontal. Existe evidencia suficiente que soporte que la remoción repetida de la placa supragingival afecta al biofilm subgingival de forma cuantitativa y cualitativa, a la vez que reduce los signos clínicos de inflamación $(11,39)$. En un estudio de revisión elaborado por Haffajee y cols. en 2003, se pone de manifiesto como los niveles de T. forsythensis y $P$. gingivalis se reducen en todas las modalidades de tratamiento comparadas (raspado y alisado radicular, terapia antibiótica con metronidazol, tartrectomía supragingival y terapia combinada), aunque su descenso más significativo se produce cuando se asocian la terapia mecánica y la farmacológica. Este hecho indica que el enfoque terapéutico que se debe llevar a cabo contra el biofilm de la placa bacteriana tiene que estar compuesto por una terapéutica de remoción mecánica, y en los casos en los que la flora subgingival posea periodontopatógenos, fundamentalmente del cluster rojo y $A$. actinomycetemcomitans, una terapia antibiótica de apoyo.

Si bien, generalmente el estado periodontal mejora con este tipo de terapias, todavía es un tema controvertido el porqué algunos individuos, o determinadas localizaciones, no responden adecuadamente a la administración de antibióticos junto a la terapia periodontal convencional.

\section{CONCLUSIONES}

Es en este punto donde surgen las nuevas líneas de investigación sobre la resistencia bacteriana dentro de los biofilms, la patogenicidad propia de las bacterias conocidas, y las que todavía quedan por conocer, y la susceptibilidad propia del paciente para producir una respuesta inflamatoria efectiva contra los patógenos periodontales. Cabe, pues, esperar que en los próximos años surjan avances tanto en las técnicas diagnósticas como terapéuticas que nos permitan tratar de forma favorable e individualizada a cada uno de nuestros pacientes periodontales, incluso aquéllos que, a día de hoy, suponen un reto terapéutico.

\section{ABSTRACT}

It is well known in our days that periodontitis can be considered as an infectious disease with certain features in common with other diseases, but with some other features that make it different and unique, what makes it difficult to reach a good knowledge of its etiopathogenesis and, in consequence, of its treatment. Many advances in relation to the composition of the dental plaque have been done in the last years, with the aim of improving the treatments and being able to offer our patients a good clinical attention based on scientific evidence. The aim of this article is to review the literature and make emphasis on the new microbiological concepts which will give place to the future investigations about the diagnose and treatment of the periodontitis.

\section{KEY WORDS}

Biofilm, periodontopathogen bacteria, periodontal diagnose.

\section{BIBLIOGRAFÍA}

1. Contreras A, Slots J. Herpesviruses in human periodontal disease. J Periodontal Res 2000; 35: 3-16.

2. Ling L, Ho C, Wu C, Chen Y, Hung S. Association between human herpesviruses and the severity of periodontitis. J Periodontol 2004; 75: 1479-85.

3. Bascones A, Noronha S, Gómez M, González Moles M.A, Villaroel Borrego M. Tissue destruction in periodontitis: bacteria or cytokines fault? Quintessence Int 2005; 36 (4): 299-306.

4. Nishihara T, Koseki T. Periodontol 2000, 2004; 36: 14-26.

5. Bascones A, Figuero E. Las enfermedades periodontales como infecciones bacterianas. Med Oral Patol Cir Bucal 2004; 9 suppl: 92-107.

6. Socransky SS, Haffajje AD. Evidence of bacterial etiology: a historical perspective. Periodontology 2000 1994; 5: $134-44$

7. Löe $H$, Theilade E, Jensen SB. Experimental gingivitis in man. J Periodontol 1965; 36: 177-87.

8. Newman MG, Socransky SS, Savitt ED, Propas DA, Crowford A. Studies in the microbiology of periodontosis. J Periodontol 1976; 47: 373-9.

9. Tanner ACR, Haffer C, Bratthall T, Visconti RA, Socransky 
SS. A studia of the bacteria associated with advancing periodontitis in man. J Clin Periodontol 1979; 6: 278-307.

10. Slots J. The predominant cultivable microflora of advanced periodontitis. Scandinavian Journal of Dental Research 1977; 85: 114-21.

11. Umeda M et al. Effects of nonsurgical periodontal therapy on the microbiota. Periodontol 2000, 2004; 36: 98120.

12. Stoodley P, Saber K, Davies DG, Costerton JW. Biofilms as complex differentiated communities. Annu Rev Microbiol 2002: 56: 187-209.

13. Socransky SS, Haffajee AD. Dental biofilms: difficult therapeutic targets. Periodontol 2000, 2002; 28: 12-55.

14. Costerton W et al. The application of biofilm science to the study and control of chronic bacterial infections. J Clin Invest 2003; 15;112 (10): 1466-77.

15. Listgarten MA, Slots J, Rosenberg J, Nitkin L, Sullivan $P$ Oler J. Clinical and microbiological characteristics of treated periodontitis patients on maintenance care. J Periodontol. 1989 Aug;60 (8):452-9.

16. Sanz M, van Winkelhoff AJ, Herrera D, Dellemijn-Kippuw N, Simon R, Winkel E. Differences in the composition of the subgingival microbiota of two periodontitis populations of different geographic location. A comparison between Spain and The Netherlands. European Journal of Dental Science 2000;108: 383-92.

17. Yang H, Huang Y, Chou M. Occurrence of Porphyromonas gingivalis and Tanerella forsythensis in periodontally diseased and healthy subjects. J Periodontol 2004; 75: 1077-83.

18. Haffajje $A D$, Borgen $A$, Hasturk H, Feres M, López NJ, Socransky SS. Subgingival microbiota of chronic periodontitis subjects from different geographic locations. J Clin Periodontol 2004; 31: 996-1002.

19. Holmstrup P, Poulsen AH, Andersen L, Fiehn N. Oral infections and systemic diseases. Dent Clin N Am 2003; 47: 575-98.

20. Rose LF, Steinberg BJ, Minsk L. Periodontal inflammation from gingivitis to systemic disease? Compen Contin Educ Dent 2000: 21 (10A): 871-7.

21. Mattson JS, Cerutis R. Diabetes Mellitus: A review of the literature and dental implications. Compen Contin Educ Dent 2001: 22 (9): 757-73.

22. Yoshihara A, Seida Y, Hanada N, Miyazaki H. A longitudinal study of the relationship between periodontal disease and bone mineral density in community-dwelling older adults. J Clin Periodontol 2004: 31: 680-4.

23. Lagervall M, Jansson L, Bergström J. Systemic disorders in patients with periodontal disease. J Clin Periodontol 2003: 30: 293-9.

24. Madianos PN, Bobetsis GA, Kinane DF. Is periodontitis associated with an increased risk of coronary heart dise- ase and preterm and/or low birth weight births? J Clin Periodontol 2002: 29 Suppl 3: 22-36.

25. Offenbacher S y cols. Periodontal Infection as a possible risk factor for preterm low birth weight. J Periodontol 1996: 67: 1103-13.

26. Scannapieco FA, Mylotte JM. Relationship between periodontal disease and bacterial pneumonia. J Periodontol 1996: 67: 1114-22.

27. Beck J y cols. Periodontal disease and cardiovascular disease. J Periodontol 1996: 67: 1123-37.

28. van Steenbergen TJM, Petit MDA, Scholte LHM, van der Velden U, de Graaff J. Transmision of Porphyromonas gingivalis between spouse. J Clin Periodontol 1993: 20: 3405.

29. Greenstein G, Lamster I. Bacterial transmission in periodontal diseases: a critical review. J Periodontol 1997: 68: 421-31.

30. Preus HR, Zambon JJ, Dunford RG, Genco RJ. The distribution and transmission of Actinobacillus Actinomycetemcomitans in families with established adult periodontitis. J Periodontol 1994: 62: 2-7.

31. Preus HR, Olsen I. Possible transmission of A. actinomycetemcomitans from a dog to a child with rapidly destructive periodontitis. J Periodont Res 1988; 23: 6871 .

32. Greenstein G. Microbiologic assessments to enhance periodontal diagnosis.. J Periodontol. 1988 Aug; 59 (8): 508-15.

33. Mombelli A, Schmid B, Rutar A, Lang NP. Local antibiotic therapy guided by microbiological diagnosis. J Clin Periodontol 2002 Aug; 29 (8): 743-9.

34. Listgarten MA, Loomer PM. Microbial identification in the management of periodontal diseases. A systematic review. Ann Periodontol 2003; 8 (1): 182-91.

35. Sanz M, Lau L, Herrera D, Morillo JM, Silva A. Methods of detection of Actinobacillus actinomycetemcomitans, Porphyromonas gingivalis and Tannerella forsythensis in periodontal microbiology, with special emphasis on advanced molecular techniques: a review. J Clin Periodontol 2004; 31: 1034-47.

36. Liébana J, Castillo AM, Álvarez M. Periodontal diseases: microbiological considerations. Med Oral Patol Oral Cir Bucal 2004; 9 Suppl: 75-91.

37. Prosser BL, Taylor D, Dix BA, Cleeland R. Method of evaluating effects of antibiotics on bacterial biofilm. Antimicrob Agents Chemother 1987; 31 (10): 150206.

38. Xu KD, McFeters GA, Stewart PS. Biofilm resistance to antimicrobial agents. Microbiology 2000: 146: 547-9.

39. Haffajje AD, Arguello EI, Ximenez-Fyvie LA, Socransky SS. Controlling the plaque biofilm. Int Dent J 2003; 53: 191-9. 